\title{
A novel inverter twin wires high effect submerged arc welding equipment for steel plate welding
}

\author{
Kuanfang HE*, Zhipeng ZHOU*, Chao WANG* and Xuejun LI* \\ *Hunan Provincial Key Laboratory of Health Maintenance for Mechanical Equipment, Hunan University of Science and Technology, \\ Xiangtan, 411201, China \\ E-mail: hkf791113@163.com
}

\section{Received 9 June 2015}

\begin{abstract}
Twin wires submerged arc welding technology is an efficient way for the high-speed welding of heavy workpiece of the low carbon steel. A novel inverter twin wires high effect submerged arc welding equipment is proposed by combination of the inverter welding power source of direct current (DC)1250A and alternate current (AC) square wave 1000A, digital cooperative control and process monitoring technology. Digital cooperative control system are designed by combination of the a computer, TCP/IP based data collection and monitoring module, twin wires submerged arc welding control box and sensor detection system. The TCP/IP based data acquisition and monitoring module consist of Advanced RISC Machines (ARM) controller, A/D module, D/A module, network interface and digital I/O ports. The results of welding experiment demonstrate that the novel developed twin wires submerged arc welding equipment meets the designed requirements with strong adaptability, which achieves the functions of parameters optimization settings, digital timing control of the twin arcs, and real-time monitoring of the welding process. The proposed equipment has good application prospect in twin wires submerged arc welding of steel plate at high welding speed more than $100 \mathrm{~cm} / \mathrm{min}$ due to the strong adaptability in welding process.
\end{abstract}

Key words: Twin wires submerged arc welding, Novel equipment, Inverter welding power source, Digital cooperative control, Welding process monitoring, TCP/IP based data acquisition, Sensor detection system

\section{Introduction}

High power inverter submerged arc welding technology is an main efficient and suitable welding way for long plate structure of the low carbon steel. It has a wide range of applications in ship-building, pressure vessels, engineering machinery, piping, structural of nuclear power plant and marine structures (Li, et al., 2006, Li, et al., 2003, Liang, et al, 2004). In order to meet the requirements for the high efficient production, the twin wires and multi-wires submerged arc welding technology are the developed direction. Twin wires of the high-speed submerged arc welding are burning in the common molten pool to improve the overall inputting heat, make heat distribution better and provide sufficient liquid metal and heat into the molten pool. The heat effects of the two mutual welding arcs can reduce inputting energy of the second wire. In addition, the control performance of the energy parameters of the twin wires submerged arc welding are flexible and convenient, which gets a better welding quality at high speed and effectively avoid the defects of undercut and hump. In recent years, the overseas developed country have been produced high-speed twin wires welding equipment (Tusek,1996, Tusek,1996, Tusek, 2002, Janez and Tusek, 2000, Tusek,1998) . However, the research in terms of the high speed twin-wires submerged arc welding equipment in china is still at the initial stage (Meng, et al., 2005, He, et al., 2008, He, et al., 2011), most high efficient submerged welding equipment in current china market is no synergy control with independence of the two arc each other, the welding parameters are given by the potentiometer. Furthermore, the present management and regulation of the welding process parameters of the high efficient submerged welding equipment is not convenient, inflexibility and complicated during operation. So, the promotion and application of such equipment is limited in the case of high speed welding due to poor shape of welding seam with defects.

A new digital control based high speed twin wires submerged arc welding equipment is developed by combination of the direct current (DC)1250A and alternate current (AC) square wave 1000A inverter welding power source, digital cooperative control and process monitoring technology. The developed high efficient equipment can achieve the new high-speed welding processes for plate structure of the low carbon steel with functions of optimization settings of the welding parameters, timing control of the arcs and real-time monitoring of the welding process. The welding equipment has good application prospect due to the strong adaptability in welding process. 


\section{The constitution of the novel twin wires submerged arc welding equipment}

In order to overcome the interference caused by the two power supply source in twin wires welding, a combination of the DC and AC welding power source is always adopted as the key parts of the twin wires submerged arc welding equipment. The high power inverter welding power source in the twin wires high speed submerged arc welding system is constant current outputting characteristic implemented by its own internal current feedback control. So, the developed high efficiency inverter twin wires submerged arc welding equipment is proposed by the combination of two high-power inverter welding power source of DC1250A and AC square wave 1000A as main body, digital control system and other auxiliary device. The auxiliary device includes twin torches, wire feeder and welding walking mechanism and so on, the framework sketch is shown in Fig.1, the on-site physical picture is shown in Fig.2. Digital cooperative control system consists of a computer, controller, twin wires submerged arc welding control box and sensor detection system. The main function of the digital cooperative control system is to achieve optimization settings of welding parameters, real-time monitoring of the operating state of the welding process and cooperative control of two arcs stability.

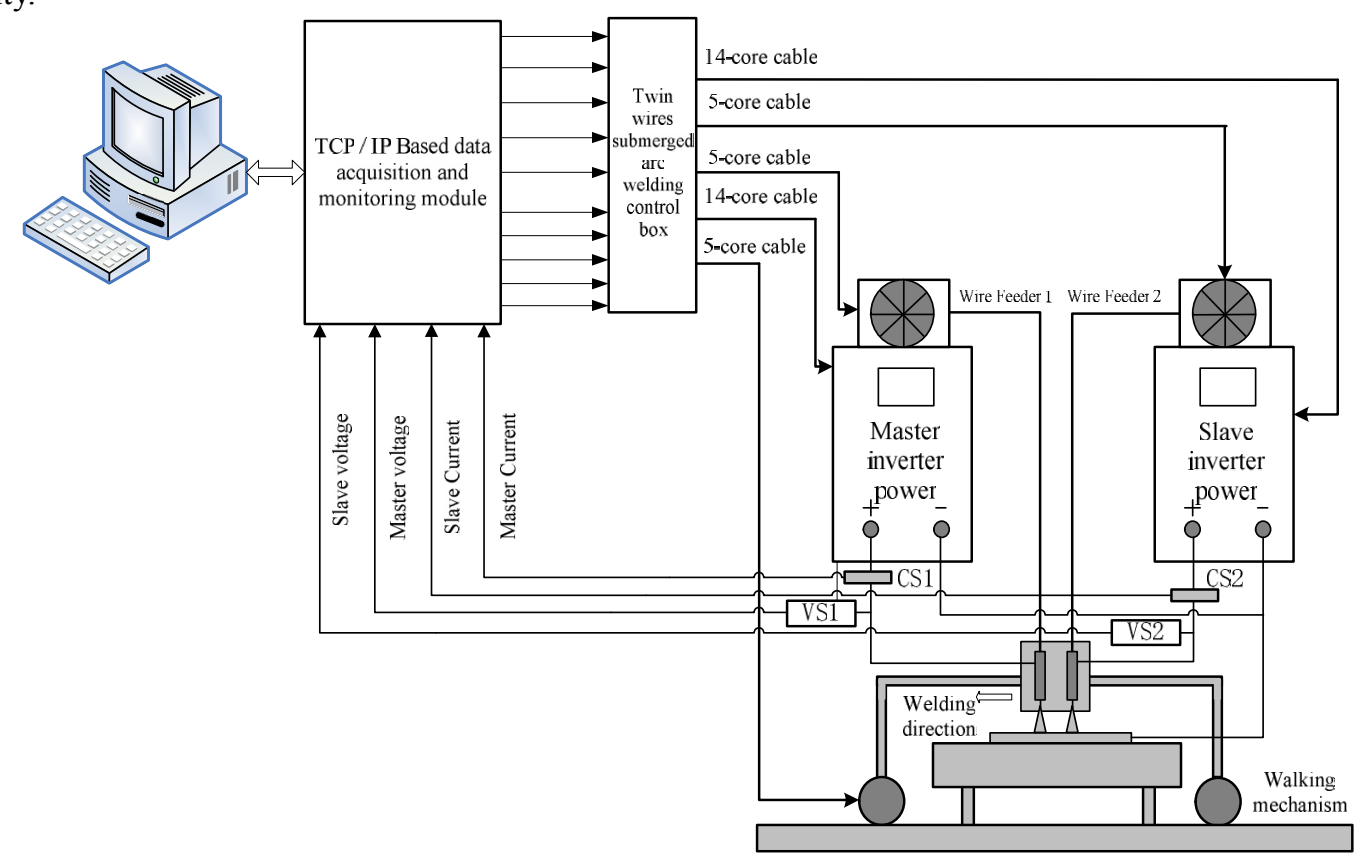

Fig.1 The framework sketch of the twin wires submerged arc welding equipment

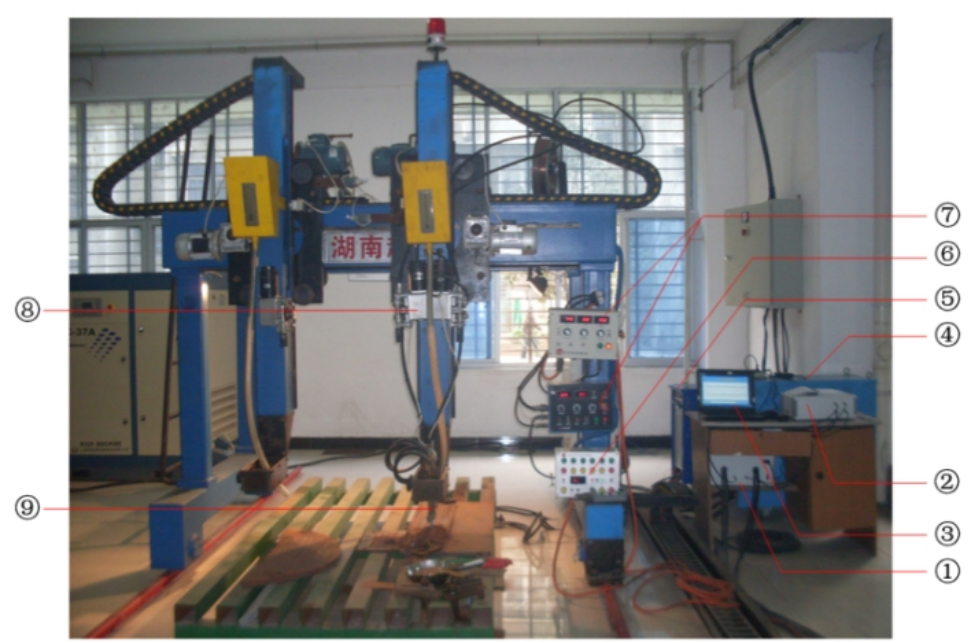

(1)Sensor box; (2)Controller; (3)Computer; (4)MZE-1000 AC power source; (5)MZ-1250 DC power source; (6)Walking control box; (7)Twin wires submerged arc welding control box; (8Wire feeder; (9)Contact tip

Fig.2 The physical map of the twin wires submerged arc welding equipment 


\section{Inverter DC/AC square wave submerged arc welding power source}

\subsection{Inverter principle of DC/AC square wave inverter}

Figure 3 shows the principle of the DC/AC square wave inverter, it is consists of DC arc welding inverter and a secondary full-bridge inverter circuit.

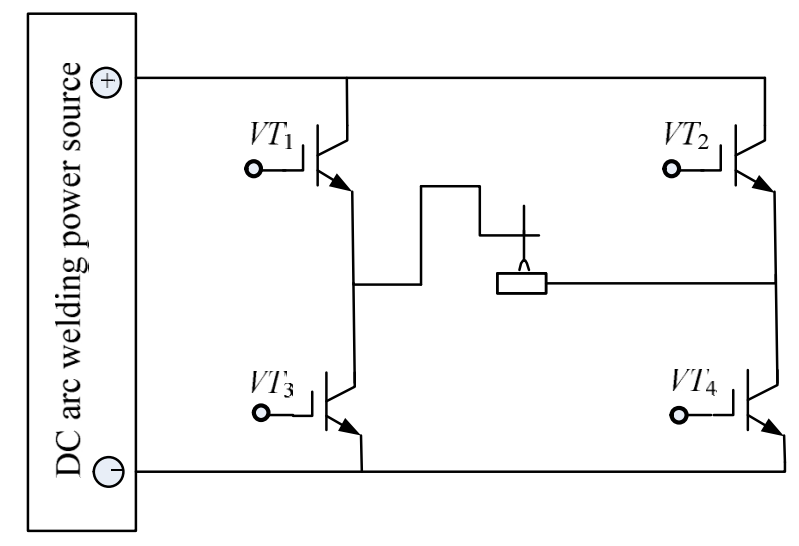

Fig.3 The principle sketch of arc welding inverter

The arc welding inverter can output DC and AC square wave currents to meet requirement the desired properties of submerged arc welding. The inverter can convert DC to AC square wave through the second full bridge circuit. The four-arms of full-bridge are composed by two pairs of IGBT $V T_{1}-V T_{4}$ and $V T_{2}-V T_{3}$ that are access to arc load respectively. When $V T_{1}-V T_{4}$ is on and $V T_{2}-V T_{3}$ is off, the DC arc welding inverter output DC current through $V T_{1}-V T_{4}$ to provide a positive polarity arc load. When $V T_{2}-V T_{3}$ is on and $V T_{1}-V T_{4}$ is off, the DC arc welding inverter output DC current through $V T_{2}-V T_{3}$ to provide a reverse polarity arc load. Controlling two groups of $V T_{1}-V T_{4}$ and $V T_{2}-V T_{3}$ to be on and off in turn at a certain time and relative proportions, the different frequency, polarity and duty cycle of the AC square wave arc waveform can be obtained. The no-load outputting voltage and the external characteristics of AC square wave arc welding inverter are achieved through the regulation and control of the DC arc welding inverter.

\subsection{Parallel working principle of twin full-bridge arc welding inverter}

An approach of the improvement of current outputting capacity and solution of reliable problem in inverter parallel running is adopted the limiting current method to each full-bridge inverter in the parallel topology of the main circuit. The current limiting parallel principle of twin full-bridge AC square wave arc welding inverter is shown in Fig.4. The

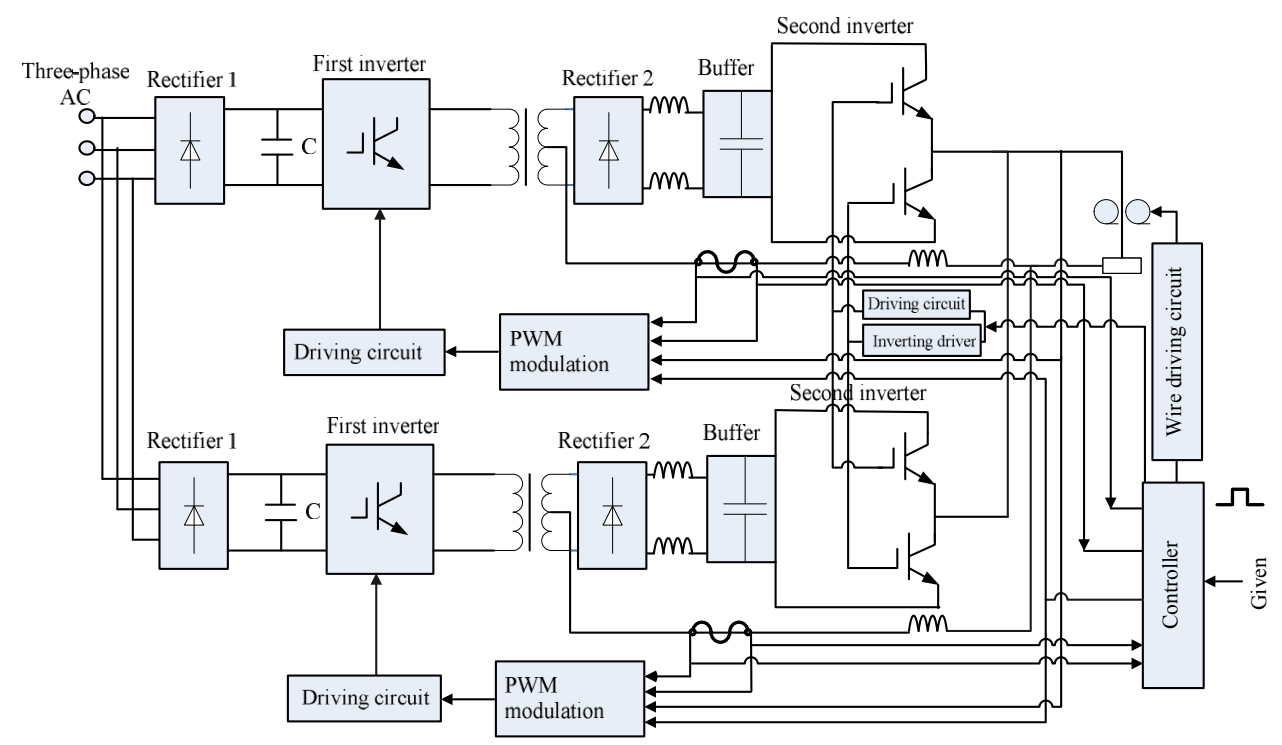

Fig.4 The current limiting parallel principle of twin full-bridge AC square wave arc welding inverter

rating outputting capacity is improved by parallel operation of the two full-bridge inverter, the outputting current of the 
parallel inverter reaches basically equilibrium through current limiting control by the current negative feedback.

Figure 5 shows outputting current and voltage waveforms of the AC square wave welding power source. As can be seen from Fig. 5 that the speed of curves crossing zero is fast, the waveform is smooth and stable. The dynamic characteristic of such AC square wave arc welding inverter and the crossing zero speed of the welding current have great influence on the stability of the arc.

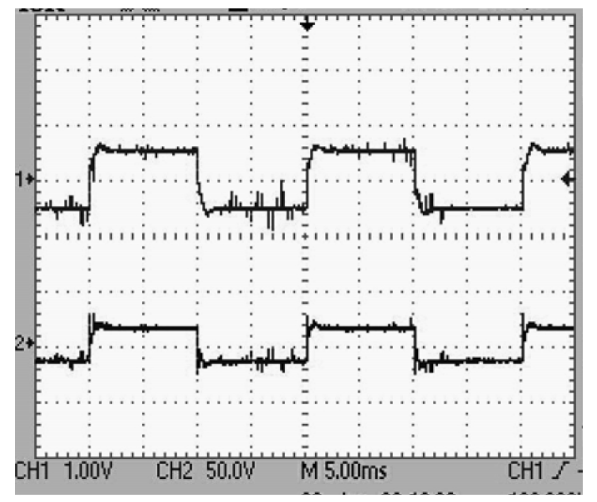

(a) Outputting current $400 \mathrm{~A}$, voltage $14.2 \mathrm{~V}$

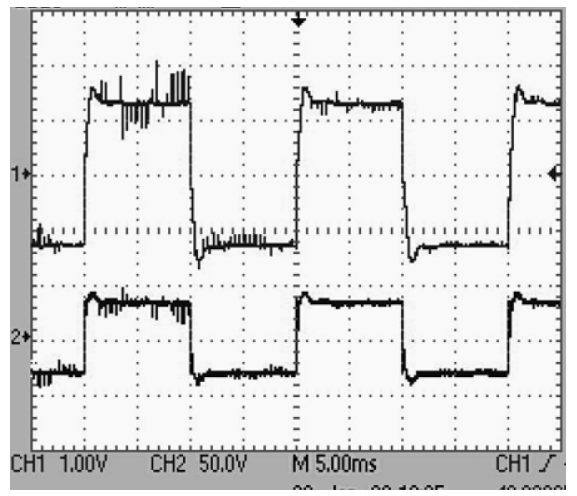

(b) Outputting current $900 \mathrm{~A}$, voltage $31.2 \mathrm{~V}$

(1-I: 400A/div, 2- $U: 50 \mathrm{~V} /$ div, Frequency: $50 \mathrm{~Hz}$, Duty cycle: 0.5 )

Fig. 5 Waveforms of AC square wave current and voltage of submerged arc welding

\section{Digital cooperative control system}

The interface part of the digital control system and the welding equipment is the cooperative controller and twin wires submerged arc control box, which includes three types of inputting and outputting channels. The first kind channel is I/O interface, of which the task is to transmit the digital signal from the computer to switching devices in the twin wires submerged arc welding control box such as the on and off states of inverter power source, wire feeder and walking mechanism. The second kind channel is $\mathrm{D} / \mathrm{A}$ converter, of which the responsibility is parameters settings of the welding current, voltage and speed. The third kind channel is A/D converter, of which the responsibility is collecting of the welding current, voltage and speed that are sent to the computer for real-time processing and display. In order to prevent interference from the high voltage part, all inputting and outputting channels using optical isolation technology. The digital cooperative control hardware system of twin wires submerged arc welding is shown in Fig.6.

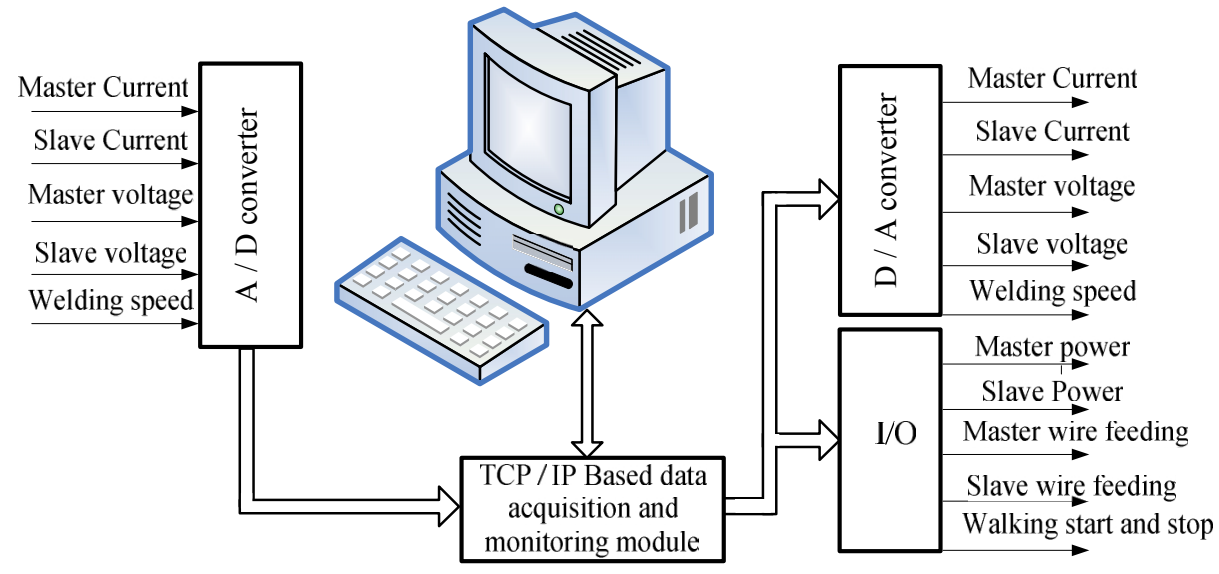

Fig.6 The digital cooperative control hardware system

The software of digital cooperative control system is designed for twin wires submerged arc welding equipment. The requirements of the adaptability and running stability of system software are important in complex cooperative control process. The software of digital cooperative control system is designed by modular programming, which is divided into different functional modules based on the functions of control system. The functions of the software are used to complete the synergy control of the welding parameters in the starting and ending process of the twin arcs, achieve digital processing for the sampling signal and real-time monitoring of welding parameters in the welding process. 
According to the above requirements, the software is designed by four parts, which are the stages of preparation for the master and slave machine before welding, the starting arc, the real-time monitor and control in welding process and the ending arc. The programs from master-slave machine are achieved by cooperative control. The programs of the cooperative control are written as the functions of the parameters presetting, timing control of starting arc, real-time monitoring in welding process, timing control of ending arc and data communication. The main functions and flow chart are designed as follows:

(1) Parameters presetting function is used to set the welding parameters, it is expressed as Csyzhs with the function returning value of $F_{1}, F_{2}$ and $F_{3}$ that are used to determine the validity of the parameters setting. The flow of this function is shown in Fig.7. The parameters settings interface firstly displays the electrical parameters of welding current $I_{1} 、 I_{2}$, welding voltage $U_{1} 、 U_{2}$ and welding speed $v$ when call for the function.

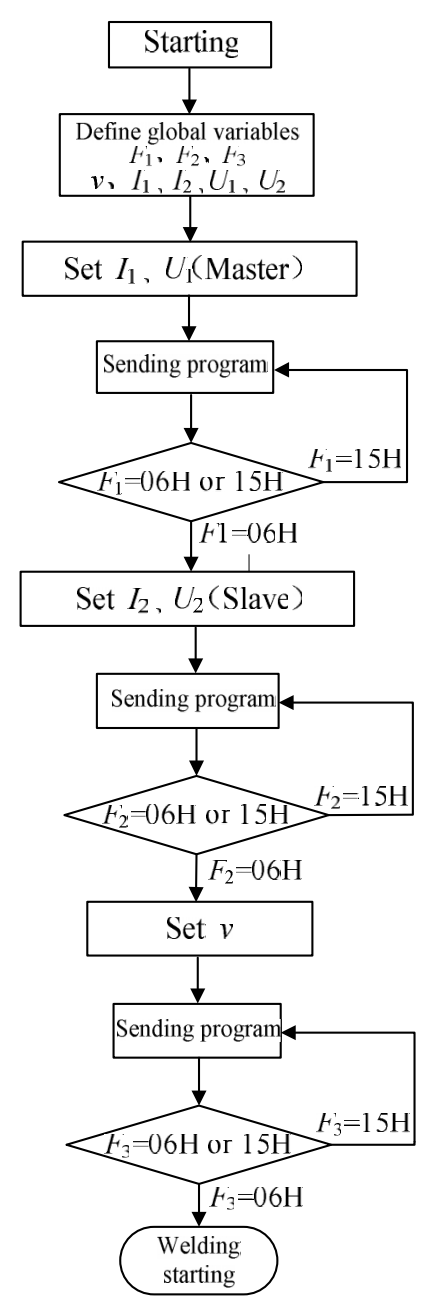

Fig.7 Preset parameters



Fig.8 Control of starting arc

(2) The control function of starting arc is used for timing control of twin arc, it is expressed as Qhkzhs with the function returning value of $F_{\mathrm{q} 1}, F_{\mathrm{q} 2}$ and $F_{\mathrm{q} 3}$ that are used for judging whether the arc starting is successful, when the values of $F_{\mathrm{q} 1}$ and $F_{\mathrm{q} 3}$ are one means arc starting is successful, when $F_{\mathrm{q} 1}$ and $F_{\mathrm{q} 3}$ are zero means arc starting is failure. $F_{\mathrm{q} 2}$ is used to determine whether the delay time is $T$ when the former wire is arc starting. $T$ is the time required for moving across the wires spacing $l$ at welding speed of $v$. The flow chart of the function is shown in Fig.8. This function is called for achieving arc starting of the twin wires at a certain timing.

(3) The monitoring function of welding process is expressed as Hjgcjchs, the function returning value are set by $I_{\mathrm{X} 1}$, $I_{\mathrm{X} 2}, U_{\mathrm{X} 1}$ and $U_{\mathrm{X} 2}$ that are used to display the collected current and voltage signals. The currents and voltages of the master and slave welding machine are the real-time collected and displayed during operation of the function. The flow chart of the function is shown in Fig.9.

(4) When the welding is stopped, the control function of arc ending is called for, which is expressed as Shkzhs with the function returning value of $F_{\mathrm{s}}$ that is used to determine whether arc ending is successful. The flow chart of 
function is shown in Fig.10. In order to get a good effect of arc ending, we need call for this function to achieve arc ending of the twin wires at a certain timing.

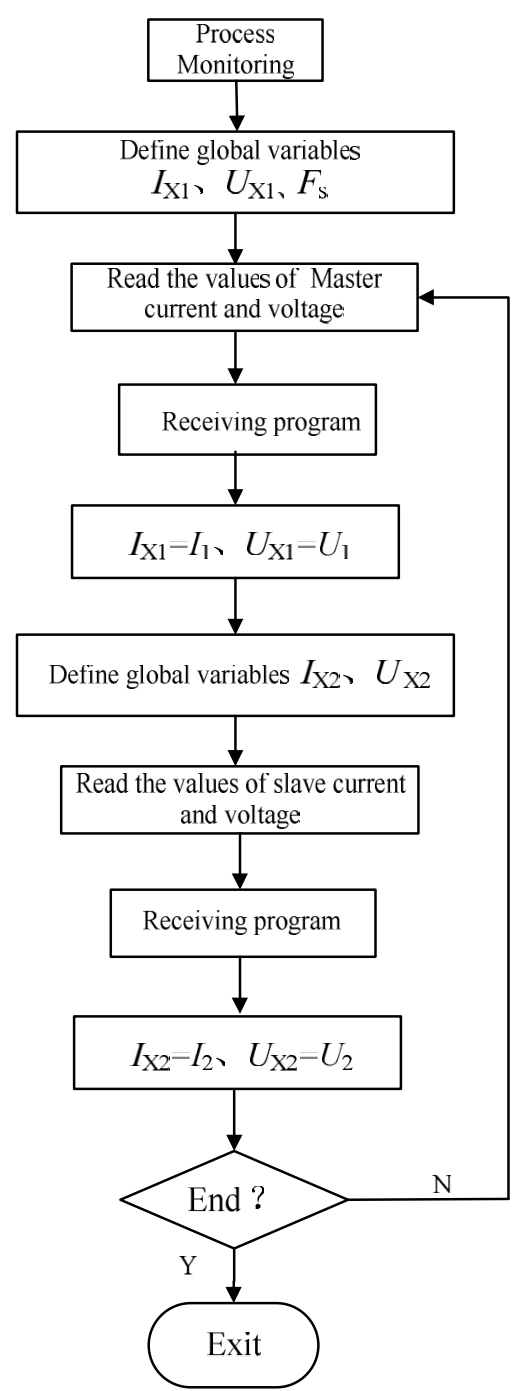

Fig.9 The welding process monitoring

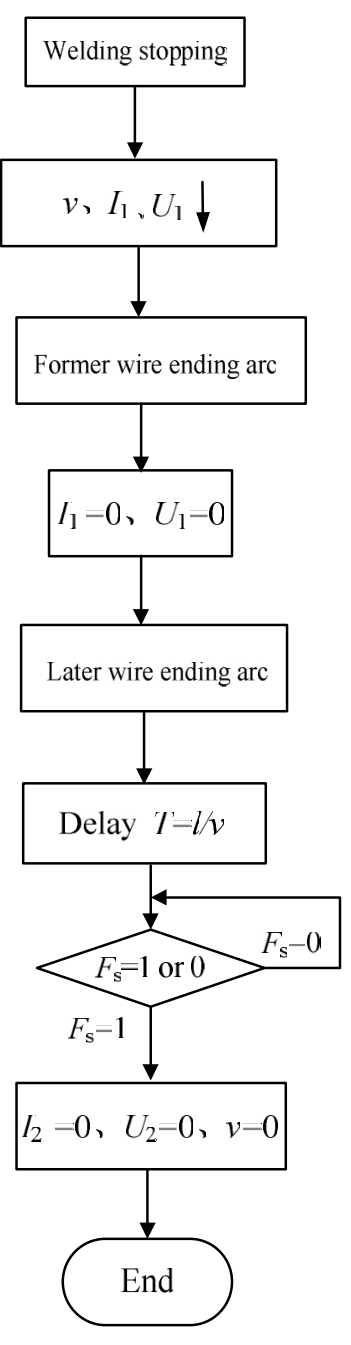

Fig.10 Control of ending arc

\section{Online monitoring technology of twin wires submerged arc welding}

The online monitoring system of welding process consists of a computer, TCP / IP based data collection and monitoring module. Each part arranged in the twin wires submerged arc welding equipment is shown in Fig.1, the physical map of online monitoring system is shown in Fig.11. In real-time monitoring of the welding process, the current and voltage of the master and slave arcs are detected in real time by current sensors of CS1 and CS2 and voltage sensors of VS1 and VS2, of which the sensors are non-contact current and voltage Hall types. The data acquisition and

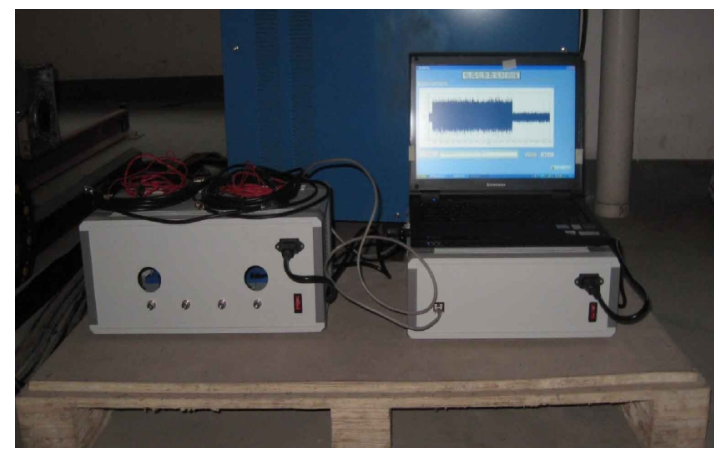

Fig.11 The physical map of online monitoring system 
monitoring module based on TCP/IP is the core of this system, which is responsible for collection of the signals, communication with the host computer and the execution of control instruction. The computer is used for setting of the welding parameters and inputting of the controlling instruction, in which the software displays the voltage and current state in real time. In addition, the sensors, data acquisition module and computer can be combined with the cooperative controller as a feedback system to achieve closed-loop control of welding current and voltage, which ensures the stability of the welding process.

The TCP/IP based data acquisition and monitoring module consist of ARM controller, A/D module, D/A module, network interface and digital I/O ports, which is shown in Fig.12. The Ethernet module is used for two-way communication with advantages of high data transmission rate, large transmission capacity, strong anti-interference ability compared to data transmission modes of the Universal Serial Bus (USB), Recommended Standard 232 (RS-232) and Peripheral Component Interconnect (PCI).

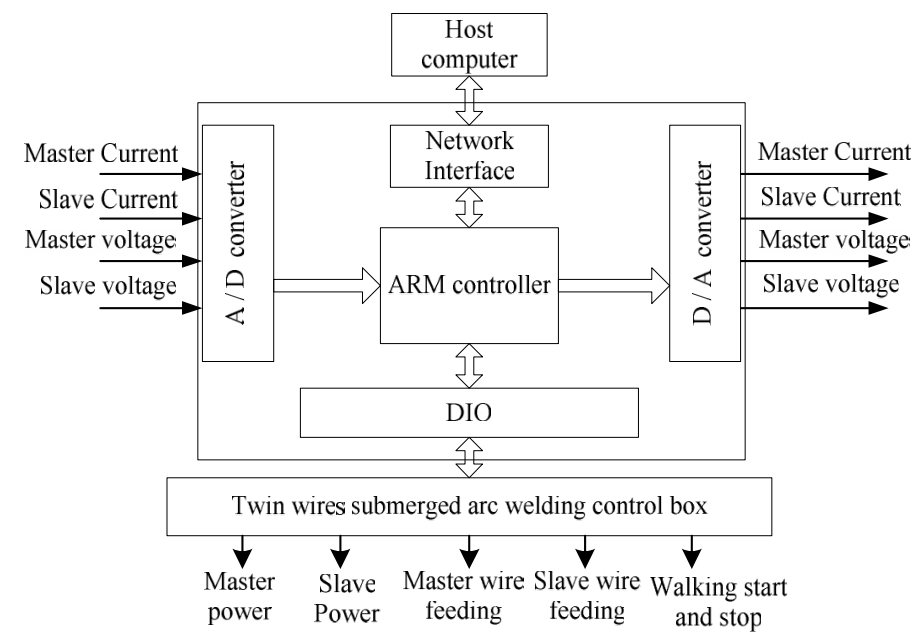

Fig.12 TCP / IP Based data acquisition and monitoring module

Figure 13 is the flow chart of the data acquisition. The process of data acquisition is begin with the power to the

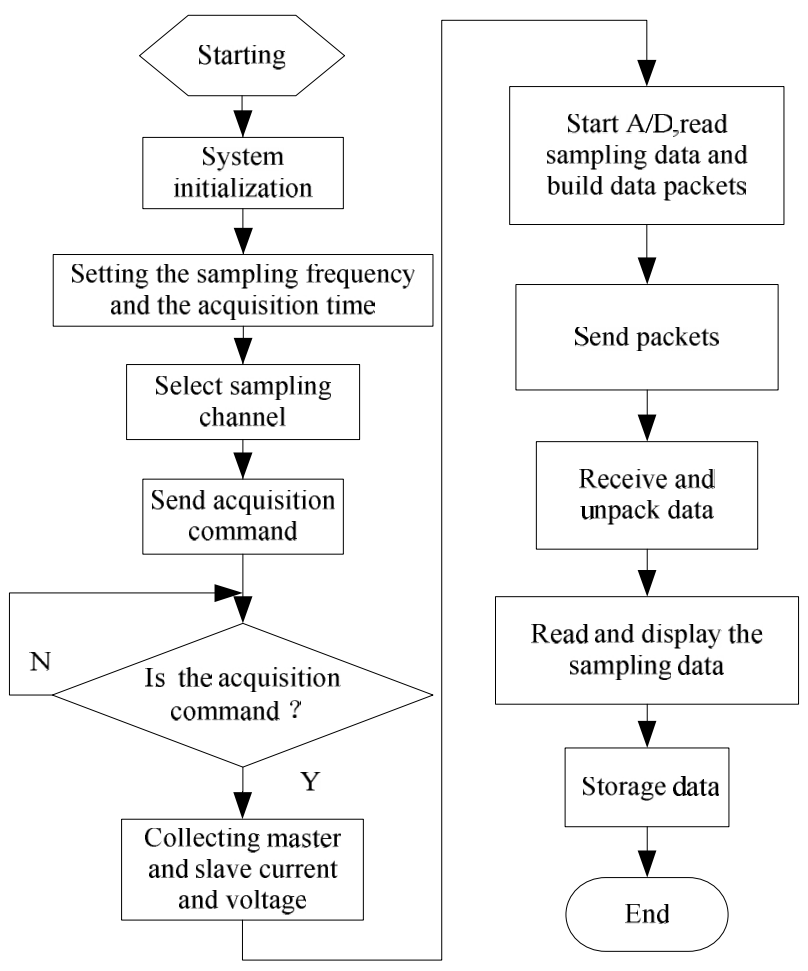

Fig.13 The flow chart of data acquisition 
system, and the data acquisition software system is run following with the sets of the acquisition frequency, channels and time. The system is in the waiting state when initialization of hardware is completed. When the data acquisition unit receives the collection starting command, the data of the currents and voltages are collected and sent to the computer by the Ethernet interface. When computer unit receives the data through the Ethernet interface, the data of current and voltage signals are displayed and storage by the software.

\section{Experiment}

The technology and testing experiment are done for validation of the novel developed twin wires submerged arc welding equipment based on digital cooperative control. The welding experiment conditions are set as following: the welding power supply source are adopted by combination of MZ1250 and MZE1000 inverter, the low carbon steel plate of thickness $20 \mathrm{~mm}$ is taken as the welding object, the welding wire brand is H08A with the former wire diameter of $\Phi 5 \mathrm{~mm}$ and the later one of $\Phi 4.8 \mathrm{~mm}$, welding flux brand is HJ431. Under the experiment condition, the sampling frequency and channels of the computer monitoring system are selected to ready for the process testing. The process specification parameters are shown in Table 1, the corresponding waveforms of current and voltage are shown in Fig.14 as well as the welding seam appearances. It can be seen from the figures that the real-time acquisition and storage of the current and voltage signals can be realized by the monitoring system. The welding process is stable, the formation effect of welding seam is good and the welding appearance at positions of the starting and ending of the arc are improved. The experiment prove the validity of the developed twin wires submerged arc welding automatic equipment that is suitable for the twin wire submerged arc welding.

Table 1 The process parameters and welding condition of twin wires submerged arc welding

\begin{tabular}{|c|c|c|c|c|c|c|}
\hline \multicolumn{2}{|c|}{$\begin{array}{c}\text { Welding } \\
\text { current(A) }\end{array}$} & \multicolumn{2}{|c|}{$\begin{array}{c}\text { Welding } \\
\text { voltage }(\mathrm{V})\end{array}$} & \multirow{2}{*}{$\begin{array}{l}\text { Welding speed } \\
(\mathrm{m} / \mathrm{min})\end{array}$} & \multirow{2}{*}{$\begin{array}{l}\text { Welding wire } \\
\text { distance } \\
\text { (mm) }\end{array}$} & \multirow{2}{*}{ Welding condition } \\
\hline $\begin{array}{l}\text { Former } \\
\text { wire }\end{array}$ & $\begin{array}{l}\text { Later } \\
\text { wire }\end{array}$ & $\begin{array}{l}\text { Former } \\
\text { wire }\end{array}$ & $\begin{array}{l}\text { Later } \\
\text { wire }\end{array}$ & & & \\
\hline 650 & 550 & 36 & 38 & 1.2 & 25 & $\begin{array}{l}\text { Stability of the welding } \\
\text { process and good welding } \\
\text { seam appearance }\end{array}$ \\
\hline
\end{tabular}
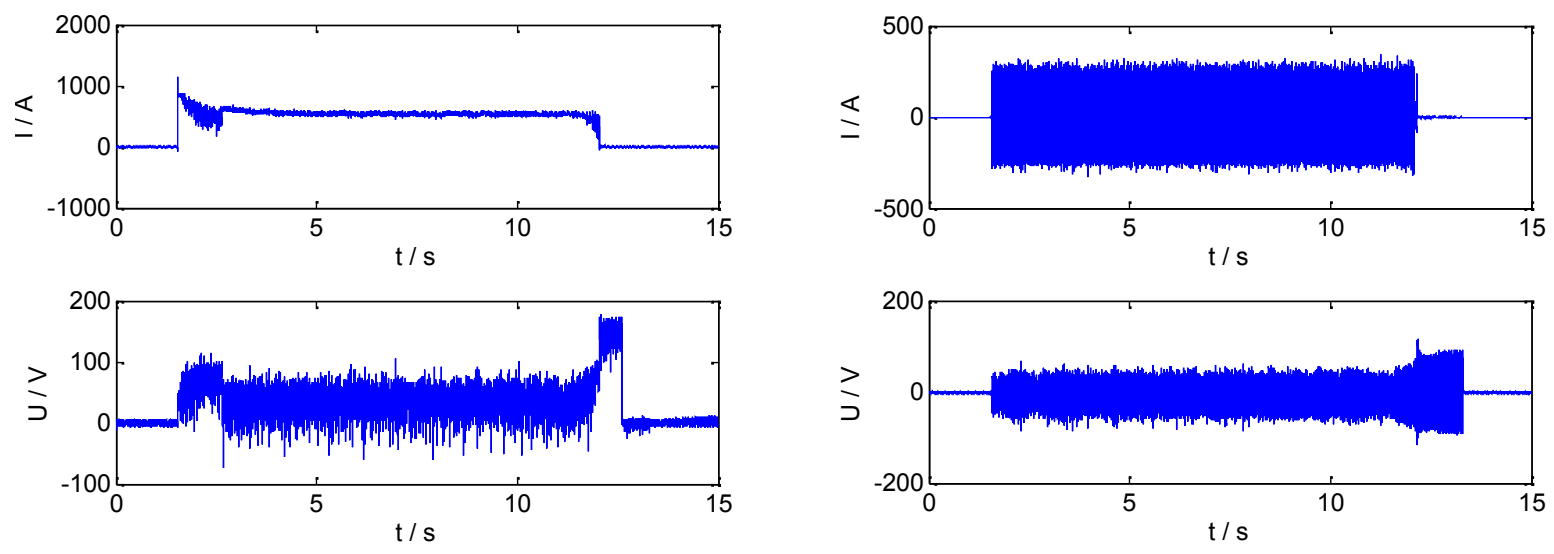

(a) The DC current and voltage waveforms of the former wire

(b)The AC square wave current and voltage waveforms of later wire

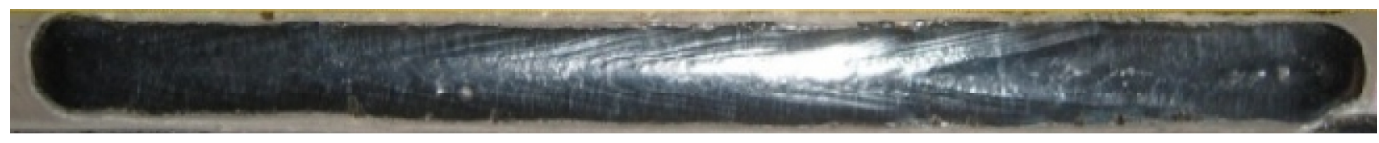

(c) The welding seam appearance

Fig.14 The welding current and voltage waveforms and welding seam appearance

\section{Conclusions}


The high power novel combinations of DC1250A and AC square wave 1000A arc welding inverter power source is adopted as the main parts of the high efficient submerged arc automatic welding equipment, and is used to achieve the high-speed twin wires welding process. Application of the new process, it can guarantee welding quality at condition of high welding speed, greatly improve production efficiency and achieve double saving effect for the electrical energy.

Application of the digital cooperative control to the twin wires submerged arc automatic welding equipment, it can achieve functions of optimization settings of welding parameters, real-time monitoring of the operating state of the welding process and cooperative control of the twin arcs. Furthermore, The submerged arc automatic welding equipment controlled by the digital cooperative control system is more flexible and strong adaptability.

The Ethernet data transmission technology applied for the welding monitoring has the advantages of high data transmission rate, large transmission capacity, strong anti-interference ability and so on compared to the USB, RS-232 and PCI data transmission mode. It can be used to record and storage the welding arc current and voltage signal with high accuracy and high-speed for further analysis and processing.

Comparing to the traditional twin wires submerged arc welding equipment, the novel developed equipment integrates an advanced inverter power source technology, digital control and online monitoring technology, which achieves the digital high speed welding manufacturing with characteristic of flexible control. The operational efficiency and reliability of the equipment are greatly improved at high speed welding condition due to introduction of advanced computer control and sensor testing technology. Furthermore, the structure of equipment is compact with reduction of the complex hardware control circuit, and offers enough flexibility for the second design of function upgrades. The proposed equipment not only provides the basis for high speed welding manufacturing, but also technical support and reference for multi-wires high speed welding equipment design.

\section{Acknowledgment}

This work is supported by National Natural Science Foundation of China $(51475159,51005073)$, is gratefully acknowledged.

\section{References}

D.Sc.Janez, Tusek., Mathematical Modeling of Melting Rate in Twin-wire Welding, Journal of materials Processing Technology, Vol.100 (2000),pp.250-256.

He, K. F., Huang, S. S., Li, X. J., Et al. Digital Synchronic Control System for Twin-arc Co-pool High Speed Submerged Arc Weld, China Mechanical Engineering, Vol.22,No.2 (2011),pp.235-239 (in Chinese).

He, K. F., Huang, S. S., Sun, D. Y., Et al. Development of AC Square-Wave Inverter for High-Power Submerged Arc Welding, Journal of South China University of Technology (Natural Science Edition), Vol.36,No.8(2008),pp.79-82(in Chinese).

Li, H. Q., Wang, X., Cai, X. P., Et al. Developing Status of SAW at Home and Abroad, Electric Welding Machine,Vol .36,No. 4 (2006),pp.1-6(in Chinese).

Li, Y. B., Huang, S. S., Wang, Z. M., Et al. Theoretic Analysis of Static Characteristics of Novel Soft-switching Submerged Arc Welding Inverter, Journal of South China University of Technology (Natural Science Edition), Vol .31,No.5( 2003),pp.39-42(in Chinese).

Liang, W. D., Ma, Y. Z., Gao, H. Y., A Digital Controller Design for Submerged Arc Welding, Transaction of The China Welding Institution, Vol .25,No.6( 2004),pp.54-58(in Chinese).

Meng, Q. G., Fang, H. Y., Xu, W. L., Heat Source Model For Twin Wire Welding, Chinese Journal of Mechanical Engineering, Vol.41,No.4(2005),pp.110-113(in Chinese).

Tusek, J., SAW with Multiple Electrodes Achieves High Production Rates, Welding Journal, Vol .75,No.8(1996),pp.41.

Tusek, J., Narrow-gap Submerged-arc Welding with a Multiple-wire Electrode, Metalurgija , Vol .41,No.2(2002),pp.83-88.

Tusek, J., Raising Submerged Arc Welding Productivity, Fielding Review International,No.8 (1996),pp.102-105.

Tusek, J., Metal-powder Twin-wire Submerged-arc Welding, Welding \& Metal Fabrication,Vol.66,No.7(1998),pp.21-24. 